\title{
The CarbonTracker Data Assimilation Shell (CTDAS) v1.0: implementation and global carbon balance 2001-2015
}

\author{
Ingrid T. van der Laan-Luijkx ${ }^{1,2}$, Ivar R. van der Velde ${ }^{3,4,1,5}$, Emma van der Veen ${ }^{1}$, Aki Tsuruta ${ }^{6}$, \\ Karolina Stanislawska ${ }^{7}$, Arne Babenhauserheide ${ }^{8}$, Hui Fang Zhang ${ }^{9,10}$, Yu Liu ${ }^{11}$, Wei He ${ }^{5,12}$, Huilin Chen ${ }^{5,4}$, \\ Kenneth A. Masarie ${ }^{3, a}$, Maarten C. Krol ${ }^{1,2,13}$, and Wouter Peters ${ }^{1,5}$ \\ ${ }^{1}$ Meteorology and Air Quality Group, Wageningen University and Research, Wageningen, the Netherlands \\ ${ }^{2}$ Institute for Marine and Atmospheric Research, Utrecht University, Utrecht, the Netherlands \\ ${ }^{3}$ Global Monitoring Division, Earth System Research Laboratory, National Oceanic and Atmospheric Administration \\ (NOAA), Boulder, Colorado, USA \\ ${ }^{4}$ Cooperative Institute for Research in Environmental Sciences (CIRES), University of Colorado, Boulder, Colorado, USA \\ ${ }^{5}$ Centre for Isotope Research, University of Groningen, Groningen, the Netherlands \\ ${ }^{6}$ Climate Research, Finnish Meteorological Institute, Helsinki, Finland \\ ${ }^{7}$ Meteorological Research, Finnish Meteorological Institute, Helsinki, Finland \\ ${ }^{8}$ IMK-ASF, Karlsruhe Institute of Technology (KIT), Karlsruhe, Germany \\ ${ }^{9}$ State Key Laboratory of Resources and Environment Information System, Institute of Geographic Sciences and Natural \\ Resources Research, Chinese Academy of Sciences, Beijing, China \\ ${ }^{10}$ University of Chinese Academy of Sciences, Beijing, China \\ ${ }^{11}$ Institute of Biogeochemistry and Pollutant Dynamics (IBP), ETH Zurich, Zurich, Switzerland \\ ${ }^{12}$ International Institute for Earth System Science, Nanjing University, Nanjing, China \\ ${ }^{13}$ SRON Netherlands Institute for Space Research, Utrecht, the Netherlands \\ anow at: SkyData Solutions LLC, Boulder, Colorado USA
}

Correspondence to: Ingrid van der Laan-Luijkx (ingrid.vanderlaan@wur.nl)

Received: 24 February 2017 - Discussion started: 21 March 2017

Revised: 12 June 2017 - Accepted: 14 June 2017 - Published: 18 July 2017

\begin{abstract}
Data assimilation systems are used increasingly to constrain the budgets of reactive and long-lived gases measured in the atmosphere. Each trace gas has its own lifetime, dominant sources and sinks, and observational network (from flask sampling and in situ measurements to spacebased remote sensing) and therefore comes with its own optimal configuration of the data assimilation. The CarbonTracker Europe data assimilation system for $\mathrm{CO}_{2}$ estimates global carbon sources and sinks, and updates are released annually and used in carbon cycle studies. CarbonTracker Europe simulations are performed using the new modular implementation of the data assimilation system: the CarbonTracker Data Assimilation Shell (CTDAS). Here, we present and document this redesign of the data assimilation code that forms the heart of CarbonTracker, specifically meant to enable easy extension and modification of the data assimila-
\end{abstract}

tion system. This paper also presents the setup of the latest version of CarbonTracker Europe (CTE2016), including the use of the gridded state vector, and shows the resulting carbon flux estimates. We present the distribution of the carbon sinks over the hemispheres and between the land biosphere and the oceans. We show that with equal fossil fuel emissions, 2015 has a higher atmospheric $\mathrm{CO}_{2}$ growth rate compared to 2014, due to reduced net land carbon uptake in later year. The European carbon sink is especially present in the forests, and the average net uptake over 2001-2015 was $0.17 \pm 0.11 \mathrm{PgC} \mathrm{yr}^{-1}$ with reductions to zero during drought years. Finally, we also demonstrate the versatility of CTDAS by presenting an overview of the wide range of applications for which it has been used so far. 


\section{Introduction}

The CarbonTracker data assimilation system for $\mathrm{CO}_{2}$ estimates global carbon sources and sinks and was originally developed at the National Oceanic and Atmospheric Administration (NOAA) Earth System Research Laboratory (ESRL) in the period 2005-2007 (Peters et al., 2005, 2007). Subsequently, development continued in two separate branches: (1) CarbonTracker (NOAA/ESRL) and (2) CarbonTracker Europe (CTE; Peters et al., 2010), referring to the location of development. This paper describes the developments in the second branch.

The CarbonTracker data assimilation system for $\mathrm{CO}_{2}$ estimates the carbon exchange between the atmosphere, land biosphere and oceans, using atmospheric observations of $\mathrm{CO}_{2}$ mole fractions. A key element of CarbonTracker is the two-way nested TM5 transport model (Krol et al., 2005; Huijnen et al., 2010), which connects the surface fluxes to atmospheric $\mathrm{CO}_{2}$ mole fractions. The existing code base of TM5 in Fortran was, in 2005, also the basis for CarbonTracker requiring relatively little additional code to apply it as a $\mathrm{CO}_{2}$ ensemble Kalman smoother. Over time though, new requirements for CarbonTracker arose, specifically requiring new and more complex data structures and work flows to be handled, which were cumbersome to implement in Fortran, and not always compatible with the ongoing development of TM5. Many of these new requirements could be easily accommodated in a more versatile data assimilation framework. This lead to the new object-oriented implementation in the Python programming language and is called the CarbonTracker Data Assimilation Shell (CTDAS). It is designed in a modular fashion that allows for new observation types to be introduced, changes in the structure of the underlying state vector to be made, and even replacement of the transport model (e.g. the Lagrangian model STILT) or the optimization method (e.g. four-dimensional variational, 4DVar), with only minimal additional code within one module. Section 2 documents the new code and its possibilities.

In Sect. 3 we describe the setup of the latest version of CarbonTracker Europe for $\mathrm{CO}_{2}$ (CTE2016) and present its results, including carbon flux estimates that have been used in several carbon cycle studies. CTE2016 is based on the original CarbonTracker, of which one of the shortcomings concerns the relatively coarse setup of the state vector. This state vector contained scalar multiplication factors for a maximum of 240 "ecoregions": broad distributions of vegetation types across continents that are assumed to have fully correlated errors over their geographical extent. Although this choice represented a leap forward in 2007, when observations were sparse and most other inversion systems were even coarser, it has now become possible to replace it with a "gridded" state vector. In this approach, each element of the Earth's surface (typically resolved at $1^{\circ} \times 1^{\circ}$ ) is more or less independent, depending on pre-set correlation length scales and the correlation decays exponentially with distance. In Sect. 3.2 we will also show the implementation of this gridded state vector with minimal changes to the code and assess its impact on estimated $\mathrm{CO}_{2}$ surface fluxes.

Since we have already demonstrated the power of the CarbonTracker system in previous work (Peters et al., 2005, 2007, 2010), we focus here on new extensions and applications of CarbonTracker Europe, which also demonstrate the power of CTDAS. We therefore do not include observation system simulation experiments (OSSEs), which are traditionally presented alongside the implementation of a data assimilation system. CTDAS is currently used in at least seven institutes that perform ensemble data assimilation of trace gases, with applications in $\mathrm{CO}_{2}, \mathrm{CH}_{4},{ }^{13} \mathrm{CO}_{2}$, carbonyl sulfide (COS), and $\mathrm{SF}_{6}$. These applications have helped to improve its code base and test its implementation in several setups. We will show an overview of the current applications in Sect. 4.

In this paper we (1) document the CTDAS code base (Sect. 2), (2) present the setup of the latest version of the CarbonTracker Europe (CTE2016), together with the resulting carbon flux estimates (Sect. 3) and (3) demonstrate the versatility of CTDAS by presenting an overview of the applications it has been used in so far (Sect. 4).

\section{CTDAS design and implementation}

\subsection{Data assimilation in CarbonTracker}

The CarbonTracker data assimilation system for $\mathrm{CO}_{2}$ estimates carbon fluxes between the atmosphere and the surface (land biosphere and oceans), using observations of atmospheric $\mathrm{CO}_{2}$ mole fractions. At its core, CarbonTracker is an ensemble Kalman smoother application using a fixed-lag assimilation window (Peters et al., 2005) of which several flavors are used in trace gas studies (e.g. Prinn et al., 1995; Zupanski et al., 2007; Bruhwiler et al., 2005). The surface $\mathrm{CO}_{2}$ fluxes are optimized using the cost function $(J)$ that describes the system according to

$$
\begin{aligned}
J(x)= & \left(y^{\mathrm{o}}-\mathcal{H}(\boldsymbol{x})\right)^{\mathrm{T}} \mathbf{R}^{-1}\left(\boldsymbol{y}^{\mathrm{o}}-\mathcal{H}(\boldsymbol{x})\right) \\
& +\left(\boldsymbol{x}-\boldsymbol{x}^{\mathrm{b}}\right)^{\mathrm{T}} \mathbf{P}^{-1}\left(\boldsymbol{x}-\boldsymbol{x}^{\mathrm{b}}\right),
\end{aligned}
$$

where $\boldsymbol{y}$ are the atmospheric $\mathrm{CO}_{2}$ mole fraction observations, with their error covariance $\mathbf{R}$. $\mathcal{H}$ is the observation operator (TM5) that connects the observations $\boldsymbol{y}^{\mathrm{O}}$ to the scalars that modify the surface $\mathrm{CO}_{2}$ fluxes, which are contained in the state vector $\boldsymbol{x}$. Prior information on the surface fluxes is contained in the background state vector $\boldsymbol{x}^{\mathrm{b}}$ with error covariance $\mathbf{P}$. Ensemble statistics are created from 150 ensemble members, each with its own background $\mathrm{CO}_{2}$ mole fraction field. The length of the smoother window ("lag") is set to 5 weeks. Flux patterns within regions with good observational coverage (e.g. Europe and North America) are robustly resolved well within that time, while regions with low observational coverage are less well constrained. We refer the reader 
to previous publications (Peters et al., 2005, 2007, 2010) and the web page (http://www.carbontracker.eu/documentation. $\mathrm{html}$ ) for further general details on the ensemble Kalman smoother as applied in CarbonTracker.

\subsection{Motivation for CTDAS}

CarbonTracker started with $\mathrm{CO}_{2}$ data assimilation included in the TM5 Fortran code. With ongoing developments in CarbonTracker, we required a more flexible data assimilation framework, that could accommodate more complex data flows and structures, and be applied to other applications. Such frameworks for data assimilation exist, and have been successfully used across a range of applications. One example of a popular data assimilation package is the Data Assimilation and Research Test bed, DART (see http://www.image. ucar.edu/DAReS/DART; Anderson et al., 2009; Raeder et al., 2012). It offers many out-of-the-box options for data assimilation and supports a wide range of platforms and possible applications. These are primarily, but certainly not limited to, meteorological data assimilation efforts and include ensemble systems oriented on atmospheric constituents (e.g. Arellano et al., 2010). Another example is the openDA toolkit resulting from initial developments at Delft University (http:// www.openda.org/joomla/index.php), which initial focus was on hydrological applications, but was expanded to also include wave models and air quality models. Furthermore, the European Centre for Medium-Range Weather Forecasting (ECMWF) is currently developing the Object-Oriented Prediction System (OOPS) framework (Tremolet et al., 2013), which is used in their Integrated Forecasting System (IFS). These open-source frameworks aim to provide their users with an easy-to-use and well-documented data assimilation system, and in that sense would be suitable for CarbonTracker as well. However, the CarbonTracker system is characterized by a long-lag window of several weeks, and by a very expensive observation operator (i.e. a TM5 simulation). Since the application of an ensemble Kalman smoother is also not provided by any existing open-source system, we decided to implement our own data assimilation shell.

Looking at the requirements for our CTDAS, we realized that the Python language could handle the tasks needed such as basic shell scripting, use of numerical recipes, job control under UNIX, I/O in NetCDF and HDF, analysis and visualization, and even remote interfacing over TCP/IP and HTTP. Pythons' functionality for object-oriented implementation moreover suited well our desired modular design of CTDAS, with minimal code duplication and efficient use of class inheritance to build diverse pipelines for data assimilation. Specifically, we aimed to make CTDAS:

- independent of application (carbon dioxide, methane, isotope ratios, or multi-tracer);
- independent of data assimilation design (choice of state vector and observations, or optimization method for cost function minimization);

- independent of observation operator (e.g. atmospheric transport models like TM5, WRF, STILT, biogeochemical models like SiBCASA or combinations of these);

- extendible, documented, open-source (GNU GPLv3) multi-platform.

The choice to build a custom data assimilation shell for CarbonTracker and to implement it in Python, led to the development of CTDAS as presented here. The next sections provide more detailed information on the CTDAS code, including the design and implementation.

\subsection{Modular structure of CTDAS}

The CTDAS code is based on the use of seven Python classes (or templates to create objects), each representing a different part of the data assimilation system. They are visualized in Fig. 1. Three classes are referred to as "control" classes, as the objects they instantiate are used to control the ensemble data assimilation system. These three control classes are

1. Class CycleControl controls the cycling through time, succession of cycles and organization of input and output data, including checkpointing data, for each cycle. This is the only core object of CTDAS that is automatically created based on options and arguments passed along when submitting the main CTDAS job (e.g. cycle length, smoother window length (lag) and number of ensemble members).

2. Class DaSystem describes the characteristics of the current data assimilation system in terms of state vector size, covariances and locations of input files.

3. Class Platform controls operations specific to each computing platform such as submitting jobs to the queue, creating directories and settings of the environment.

The specific details for a given experiment are controlled through external run-control files (rc-files), which consist of key:value pairs that pass information to CTDAS on, e.g., the dates for which to run the experiment or the number of parameters (scaling factors) and ensemble members. For each of the three control classes CTDAS provides a "base class" describing the required methods, attributes and the expected interface when accessing these from within CTDAS. Specific applications can then inherit these base classes, and modify only those methods or attributes that differ for their specific configuration. For example, a Platform object with a method to submit a job script with a proper command (e.g. sbatch) to a specified queueing system (e.g. SLURM) can be used for a high-performance computing environment. This same 


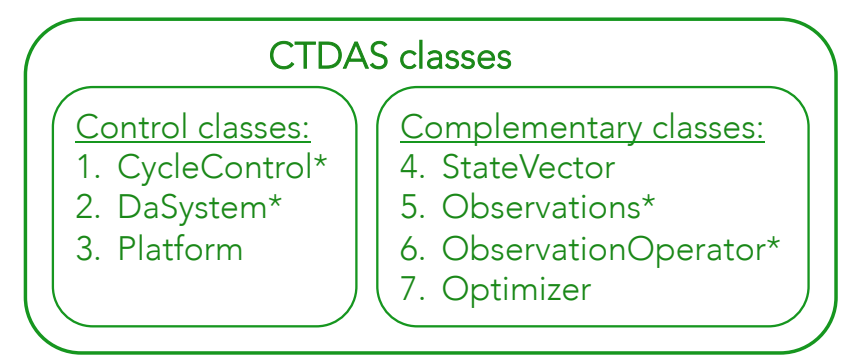

Figure 1. Overview of the seven Python classes that comprise the CTDAS code base. Asterisks indicate passing information to the code through external run-control files.

method in the Platform object could similarly prepare a job script for the next cycle on a regular workstation, but in that case could, e.g., simply spawn a new task (sh) for this job.

The four classes that complete CTDAS are

4. Class StateVector builds the data structure of a state vector, defined by three dimensions in parameter space (number of scaling factors, ensemble members and lag), including sampling of random ensemble members from a specified distribution.

5. Class Observations reads observational input data and prepares the observations to be used by the observation operator. Observation-specific information (e.g. modeldata mismatch values) is defined in and passed from an rc-file.

6. Class ObservationOperator controls the sampling of the state vector (e.g. simulating mole fractions), including, e.g., the setup, compilation and calling of the transport model.

7. Class Optimizer handles the optimization of the state vector (using, e.g., a minimum least-squares method) given a set of observations.

These seven classes represent the typical components of a data assimilation system. They are imported as objects in the main Python script and can take on many different formats depending on the application. Because the information in the Observations and StateVector classes are different for nearly every application, their dimensions and the reading of data are controlled through external rc-files that specify how to construct the corresponding objects. For the Observations class, this could for instance look like

$$
\begin{aligned}
& \text { - species: co2 } \\
& \text { - input.dir:/myfolder/observations/co2/ } \\
& \text { - input.file:\$input.dir/obspack_v1.0.nc }
\end{aligned}
$$

This external control makes it easier to use settings consistently across experiments, and also precludes the need to hard code these basic properties for each application. As long as the objects that are instantiated can parse the provided rc-file and properly populate itself with the data, the system will work.

The class Optimizer currently supports two versions of the square root ensemble Kalman smoother originally presented in Whitaker and Hamill (2002) and Peters et al. (2005), both for an observation serial algorithm and a batch algorithm. In the latter, the Kalman filter equations are solved using matrix expressions of $\mathbf{K}$ (the Kalman gain matrix), $\mathbf{R}$ and $\mathbf{H P H}{ }^{\mathrm{T}}$ rather than scalar or vector values. This can be useful when observation errors are correlated (a non-diagonal matrix $\mathbf{R}$ ). Other optimization methods (e.g. 4-D variational approach) have so far not been implemented in CTDAS, but can be added with relatively little effort by creating a new Optimizer class.

Special attention is focused on the ObservationOperator, which consumes the majority of CPU in CarbonTracker, and was previously TM5 by definition because it was the heart of the code base. Here, we have explicitly made the observation operator external to the CTDAS code and call it from a separate class. This allows TM5 to be replaced by a different transport model in CTDAS, and also enables development and maintenance of the TM5 code separate from CTDAS. In the currently implemented TM5 ObservationOperator class, an external call compiles the TM5 transport model (using Fortran and a set of TM5-specific control scripts), and this precompiled TM5 executable is subsequently called to simulate mole fraction needed in the ensemble Kalman smoother. Control of TM5 is taken over by the CycleControl object, which modifies TM5-specific input data for the current data assimilation cycle (e.g. begin and end time). The Platform object allows TM5 jobs to be run in parallel operation through the queuing system, and once finished returns control to the main Python program (CTDAS itself is currently not parallelized). This job flow is further explained in the next section, but we stress here that all references to TM5 in this paragraph can easily be replaced by that of any other transport model (e.g. WRF, GEOS-Chem or even Lagrangian transport models like STILT) as long as there is an appropriate ObservationOperator class.

\subsection{Inverse, forward and analysis pipelines}

The seven classes described above are imported as objects in the main Python script, which subsequently calls a "pipeline" script with these objects as arguments. The pipeline takes care of the order in which all steps of an experiment are performed. A key property of the pipeline is that all calls to methods in external modules (i.e., function calls) are generic, rather than specific. This means for instance that to achieve a simulation of the transport model, the generic method (e.g. run_simulation()) of an ObservationOperator is called rather than an application-specific method (such as run_tm5_with_co2()). The pipeline 
will therefore work for any ObservationOperator class with a properly programmed interface, and can be independent of specific implementations of a transport model.

The objects used in CTDAS can not only be tailored to a specific application, but also be combined in different ways, yielding different pipelines. An example is the simple "forward" pipeline, which combines the complementary Observations, StateVector and ObservationOperator objects with the three control classes. The forward pipeline simulates forward transport (ObservationOperator) of a given tracer as controlled by specified inputs (such as emission scaling factors) in the StateVector, while sampling mole fractions at all times and locations included in the Observations object. This sequence is repeated for all time steps specified in CycleControl, until the final cycle is reached. Another example is the "analysis" pipeline, combining Observations and StateVector objects with the three control classes, to extract the results from an experiment to convenient output formats (e.g. aggregated fluxes for defined regions).

A more complex pipeline, important to this paper, is the inverse pipeline that yields an actual optimization result. The pseudo-code that achieves this in CTDAS (similar to the illustration in Peters et al., 2005) is

1. Create the seven objects from the code structure (note that the first is automatically created from options and arguments when submitting the main CTDAS job; see Sect. 2.3):

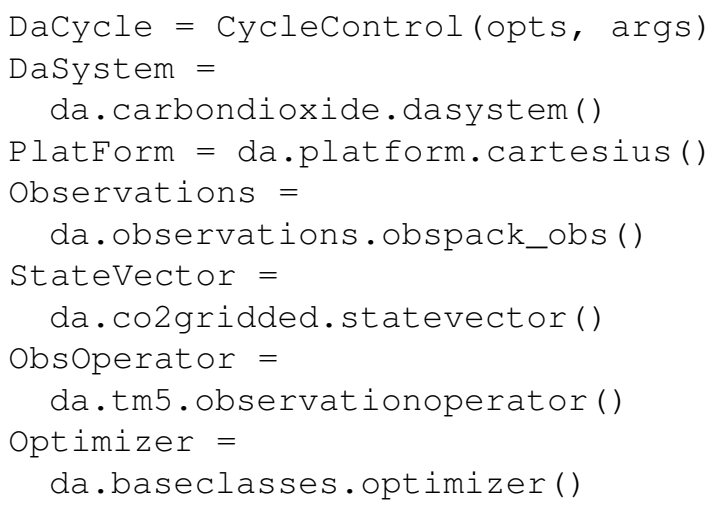

2. Read Observations $(x, y, z, t)$ for this cycle $\left(y^{o}\right)$ : Observations.read_data (Cyclecontrol.time [0])

3. Read or construct StateVector $\left(x^{b}\right)$ :

StateVector.Initialize

(Cyclecontrol.time [0])

4. Compile ObservationOperator $(\mathcal{H})$ :

Obsoperator. Compile ()

5. Run ObservationOperator for nlag cycles, and sample at $(x, y, z, t): \mathcal{H}\left(\boldsymbol{x}^{\mathrm{b}}\right)$ :

for $\mathrm{n}$ in range (nlag):

obsoperator.Run (CycleControl.time [n])
6. Optimize StateVector (from $\boldsymbol{y}^{\mathrm{o}}, \mathcal{H}\left(\boldsymbol{x}^{\mathrm{b}}\right)$ and Kalman filter equations): $\boldsymbol{x}^{\mathrm{a}}$ :

Optimizer.serial_least_squares()

7. Run ObservationOperator for $n=1$ and sample at $(x, y, z, t): \mathcal{H}\left(\boldsymbol{x}^{\mathrm{a}}\right)$ :

Obsoperator.Run (CycleControl (time [0])

As noted, this pseudo-code uses generic methods of each object and is therefore application independent.

\subsection{CTDAS documentation and version control}

The CTDAS system is documented using the open-source SPHINX package (http://sphinx-doc.org) that can export documentation written inside the code itself to various output formats including HTML, PDF, RTF and more. The output of CTDAS documentation can be viewed at http://www. carbontracker.eu/ctdas/. An important advantage of this inline documentation is that the code and its description exist within the same text files, and are thus more easily updated together. This is preferably done at the same time that the source code is modified, by the programmer doing the actual modifications. Because the syntax of this documentation is relatively simple (SPHINX handles the translation to nicely readable document formats), the burden on code developers is minimal.

\section{Updates and results from the latest version for $\mathrm{CO}_{2}$ : CTE2016}

In this section we describe the application of CTDAS for the latest version of the CarbonTracker data assimilation system for $\mathrm{CO}_{2}$ : CarbonTracker Europe (CTE2016). We focus on the updates compared to previous versions (Sects. 3.1 and 3.4), specifically related to the state vector (Sect. 3.2). For more general information on CarbonTracker we refer to previous publications (Peters et al., 2005, 2007, 2010). The differences compared to NOAA's CarbonTracker are included in Sect. 3.1.

\subsection{General setup for CarbonTracker Europe for $\mathrm{CO}_{2}$}

CarbonTracker estimates weekly scaling factors $\left(\lambda_{r}\right)$ for both net biome exchange (NBE) and net ocean exchange, using atmospheric observations of $\mathrm{CO}_{2}$ mole fractions from a global observing network. The total carbon fluxes $F(x, y, t)$ for each region $r$ (defined by longitude $x$ and latitude $y$ ) and each time step $(t)$ are represented by

$$
\begin{aligned}
F(x, y, t)= & \lambda_{r} \cdot F_{\text {bio }}(x, y, t)+\lambda_{r} \cdot F_{\text {oce }}(x, y, t) \\
& +F_{\text {fossil }}(x, y, t)+F_{\text {fire }}(x, y, t) .
\end{aligned}
$$

The scaling vectors $\left(\lambda_{r}\right)$ multiply $F_{\text {bio }}$ and $F_{\text {oce }}$, which are pre-calculated space-time patterns obtained from biosphere and ocean models (prior fluxes). Fossil fuel $\left(F_{\text {fossil }}\right)$ and 
biomass burning $\left(F_{\text {fire }}\right)$ emissions are not scaled/optimized. The monthly mean prior ocean fluxes in CTE2016 are from the ocean inversion by Jacobson et al. (2007). Earlier versions of CarbonTracker used prior biosphere and fire carbon fluxes from the CASA-GFED2 system (van der Werf et al., 2010). In CTE2016 this has been replaced by the SiBCASAGFED4 model (van der Velde et al., 2014). SiBCASAGFED4 provides net carbon fluxes for the dominant vegetation type in each $1^{\circ} \times 1^{\circ}$ grid box globally for every $3 \mathrm{~h}$. Daily fire emissions are included in these biosphere model calculations based on satellite observed burned area (Giglio et al., 2013). The seasonal development of vegetation is scaled with the satellite observed greenness (normalized difference vegetation index, NDVI) and absorption of radiation (fPAR). The fossil fuel emissions are from the EDGAR4.2 Database (2011), together with worldwide country- and sector-specific time profiles derived by the Institute for Energy Economics and the Rational Use of Energy (IER) from the University of Stuttgart and constructed for the CARBONES project (http://www.carbones.eu/). The global total fossil fuel emissions are scaled with different regional annual trends for each continent to global totals as used in the global carbon budget (Le Quéré et al., 2016) of the Global Carbon Project (GCP).

These prior fluxes are transported with the TM5 transport model (Krol et al., 2005) on a global resolution of $3^{\circ} \times 2^{\circ}$ with zoom regions of $1^{\circ} \times 1^{\circ}$ over Europe and North America. TM5 uses meteorological driver data from the ERAInterim reanalysis (Dee et al., 2011) from the ECMWF. The convective entrainment and detrainment fluxes are obtained directly from the ERA-Interim data, whereas in earlier versions we used the Tiedtke convection scheme (Tiedtke, 1989). The resulting $\mathrm{CO}_{2}$ mole fractions are compared to atmospheric $\mathrm{CO}_{2}$ observations and their differences are minimized using the ensemble Kalman smoother (using 150 ensemble members), by adjusting the flux scaling vectors $\left(\lambda_{r}\right)$ resulting in optimized posterior fluxes. The background scaling factors $\left(\lambda^{\mathrm{b}}\right)$ for each new time step $t$ are chosen as the average of the optimized scaling factors $\left(\lambda^{\mathrm{a}}\right)$ from the two previous time steps, and the fixed prior value, as in

$\lambda_{t}^{\mathrm{b}}=\left(\lambda_{t-2}^{\mathrm{a}}+\lambda_{t-1}^{\mathrm{a}}+\lambda^{\mathrm{p}}\right) / 3.0$.

The $\mathrm{CO}_{2}$ mole fraction observations are from the $\mathrm{Ob}$ sPack product: GLOBALVIEWplus v2.1 (ObsPack, 2016). CTE2016 assimilates discrete (flask) samples as well as hourly values for well-mixed conditions (afternoon hours for most locations, and nighttime hours for mountain locations).

The current setup of CarbonTracker Europe for $\mathrm{CO}_{2}$ (CTE2016) has several differences compared to the current version of CarbonTracker at NOAA (CT2016). We document here the most important differences:

- CTE2016 uses CTDAS, CT2016 uses the implementation in TM5.
- CTE2016 uses two zoom regions in TM5 (over both North America and Europe), CT2016 uses a zoom over North America.

- CT2016 applies a larger a priori flux uncertainty on land regions than CTE2016.

- CTE2016 uses the gridded state vector (Sect. 3.2), CT2016 uses the ecoregion state vector.

- CTE2016 and CT2016 use different prior fluxes for biosphere, ocean, fires and fossil fuels.

- CTE2016 and CT2016 use different subsets of $\mathrm{CO}_{2}$ observations.

\subsection{The gridded $\mathrm{CO}_{2}$ state vector}

Previous releases of CarbonTracker applied the same scaling factor for the biosphere fluxes $\left(\lambda_{r}\right)$ to all grid boxes that share the same "ecoregion" type, which means they have a similar dominant land-cover type within a broader continental region (e.g. European Croplands). The land-cover types are defined by the Olson ecosystem classification (Olson et al., 2002), and the continental regions follow the TransCom definitions (Gurney et al., 2002). This approach implies that errors in the pre-calculated biospheric fluxes are fully correlated over the ecoregion, and adjustments needed to match atmospheric $\mathrm{CO}_{2}$ mole fractions must be applied to all grid boxes of that ecoregion (proportional to the magnitude of the flux because of the linear scaling). Although this might be realistic within the context of the biosphere model that uses the same parameterizations for the same land-use types, this assumption can be questioned for actual carbon fluxes. Especially when ecosystems are geographically far apart (such as coniferous forests along the east and west coast of boreal North America), their responses to similar weather forcings might be quite different because of differences in, e.g., age structure, or management regime.

A more realistic alternative is to assume no error correlations in the biosphere fluxes over space, an approach supported by independent research based on observations (Chevallier et al., 2010). However, since the density of the observing network does not allow each ecosystem in the world to be monitored and optimized independently, many other data assimilation systems assume that correlations between regions decay exponentially as a function of distance. This correlation length scale is chosen mostly based on practical considerations, and can vary from a few $100 \mathrm{~km}$ to more than $1000 \mathrm{~km}$ (e.g. Chevallier et al., 2010; Rödenbeck et al., 2003; Basu et al., 2013). Effectively, this correlation strongly reduces the number of degrees of freedom in the covariance matrix $\left(\mathbf{P}^{\mathrm{b}}\right)$ of the scaling factors, balancing it with the number of observations. For instance, a gridded state vector for land fluxes at $5^{\circ} \times 4^{\circ}$ resolution has around 1000 land grid boxes, but only about 60 degrees of freedom when using a length scale of $1000 \mathrm{~km}$ (Peylin et al., 2013). 
Table 1. Gridded state vector setup per TransCom land region and for global ocean regions, including details on the covariance, length scale, number of parameters and degrees of freedom (d.o.f.).

\begin{tabular}{lllrrr}
\hline TransCom region & State vector & Covariance & Length Scale & Parameters & d.o.f. \\
\hline North America boreal & gridded & within ecoregions & $300 \mathrm{~km}$ & 1865 & 184 \\
North America temperate & gridded & within ecoregions & $300 \mathrm{~km}$ & 1213 & 242 \\
South America tropical & ecoregion & across ecoregions & - & 19 & 3.2 \\
South America temperate & ecoregion & across ecoregions & - & 19 & 2.9 \\
Northern Africa & ecoregion & across ecoregions & - & 19 & 3.2 \\
Southern Africa & ecoregion & across ecoregions & - & 19 & 2.5 \\
Eurasia boreal & gridded & within ecoregions & $1000 \mathrm{~km}$ & 2396 & 63 \\
Eurasia temperate & gridded & within ecoregions & $1000 \mathrm{~km}$ & 2631 & 129 \\
Tropical Asia & ecoregion & across ecoregions & - & 19 & 2.5 \\
Australia & ecoregion & across ecoregions & - & 19 & 3.4 \\
Europe & gridded & within ecoregions & $200 \mathrm{~km}$ & 1585 & 435 \\
\hline Oceans & ocean regions & across ocean regions & - & 30 & 7 \\
Ice (not optimized) & - & - & - & 1 & - \\
\hline
\end{tabular}

In CTDAS, we adopted this approach, enhanced with ecoregion information through the covariance, and implemented a gridded state vector for the Northern Hemisphere land regions on $1^{\circ} \times 1^{\circ}$ resolution. We still apply the regionbased state vector to all ocean regions as well as the Southern Hemisphere ecoregions. To manage the degrees of freedom we use this approach only for the land TransCom regions of the Northern Hemisphere which are best constrained by observations, and we furthermore use variable length scales reflecting this observation network density. Moreover, in TransCom regions with a gridded state vector we limit the correlations to exist only between grid boxes within the same Olson ecoregion (Olson et al., 2002), such that a priori errors in forest fluxes do not correlate with errors in crop fluxes even if they are dominant in neighboring grid boxes. The chosen prior standard deviation $(\sigma, \mathrm{SD})$ is $80 \%$ on land parameters, and $40 \%$ on ocean parameters, reflecting more prior confidence in the ocean fluxes than in terrestrial fluxes, because of the lower variability and larger homogeneity of the ocean fluxes. The maximum covariance is therefore 0.64 $\left(\sigma^{2}\right)$ for land parameters. The structure of the new gridded state vector is summarized in Table 1, showing a total number of 9835 scaling factors to be estimated each week, with close to 1100 degrees of freedom. An example of the covariance for a specific grid box in the European conifer forest region is given in Fig. 2.

Within the new CTDAS system, the implementation of this new gridded state vector required the creation of (1) a new global map that numbers each $1^{\circ} \times 1^{\circ}$ grid box according to its associated state vector element $(N=1, \ldots, 9835)$, and (2) an a priori covariance matrix for this new state vector, (3) a new DaSystem class (see Sect. 2.3) that defined the state vector size for this new configuration and, finally, (4) a new StateVector class (GriddedStateVector), which inherited all methods from the base class StateVector (see Sect. 2.3), and

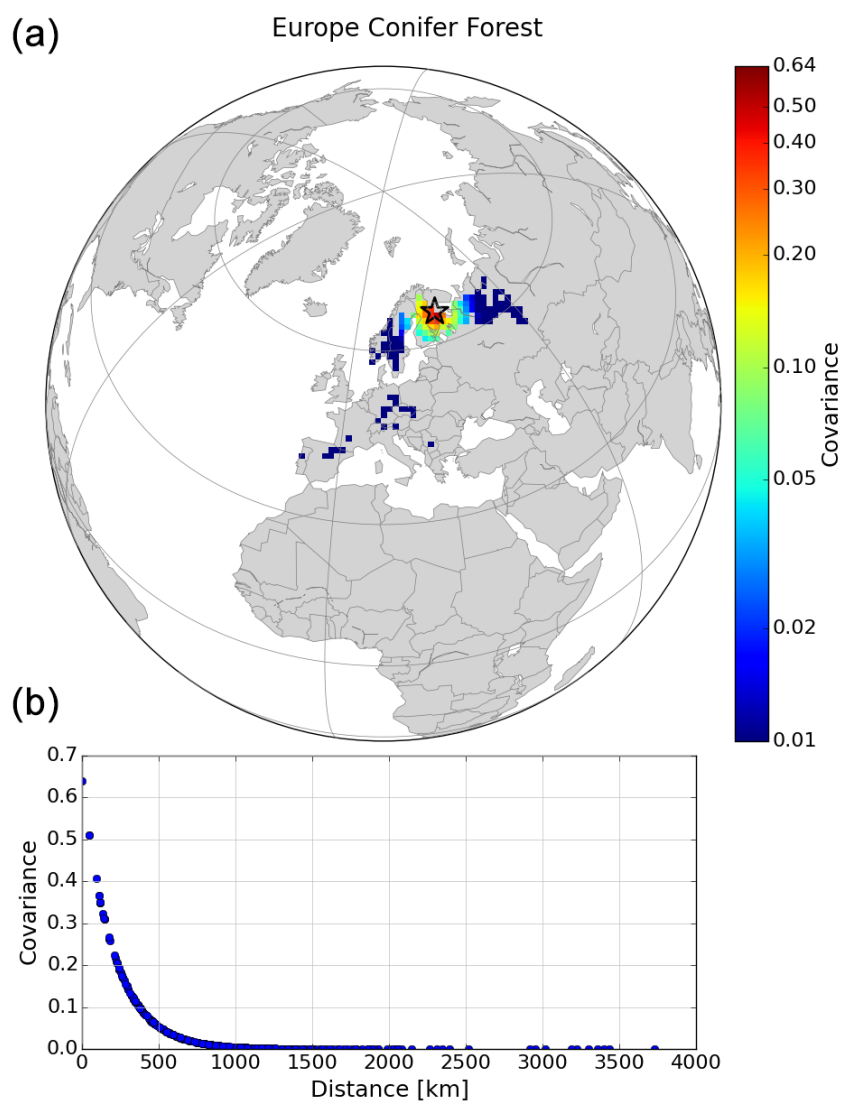

Figure 2. Error correlation in the gridded state vector setup for a specific grid box (indicated by the black star) in the European conifer forest region (with length scale $200 \mathrm{~km}$ ) with the other grid boxes in that region (a) and vs. distance (b). 
in addition had modified methods to efficiently read the covariances and create ensemble members. This implementation is also flexible and can be used easily in other applications with different setups of the state vector (see Sect. 4).

\subsection{CTE2016 results}

We have started providing annual releases of the carbon flux estimates from CarbonTracker Europe since 2013. The current version is CTE2016 and includes carbon flux estimates for 2001-2015. CTE2016 uses the gridded state vector (Sect. 3.2). Other general details of the setup and e.g. prior fluxes are described in Sect. 3.1. Carbon fluxes are estimated for the period 2001-2015 and are shown annually for the global scale in Fig. 3. This figure shows the imposed fossil fuel and biomass burning emissions and the resulting net ocean and land sinks. The natural $\mathrm{CO}_{2}$ sinks show considerable interannual variability, mainly due to climatic differences between the years. Since the land and ocean sinks are calculated from the emissions and the observed atmospheric $\mathrm{CO}_{2}$ mole fractions, they reflect the interannual variability in the atmospheric growth rate. Figure 3 also shows the comparison of the total fluxes estimated by CTE2016 with the global atmospheric $\mathrm{CO}_{2}$ growth rate as observed at background sites from the NOAA ESRL network (Dlugokencky and Tans, 2017). The growth rates are converted from $\mathrm{ppm} \mathrm{yr}^{-1}$ to $\mathrm{PgC} \mathrm{yr}^{-1}$ using $2.12 \mathrm{PgC} \mathrm{ppm}^{-1}$ (Prather et al., 2012; Joos et al., 2013). The total fluxes from CTE2016 match the observed atmospheric growth rate and its interannual variability well (up to $0.3 \mathrm{ppm} \mathrm{yr}^{-1}$ ). The remaining differences reflect differences not only due to observation sites included in either the data assimilation or the calculation of the global growth rate, but also due to, e.g., transport model errors and a time delay, since fluxes of the end of a year influence the atmospheric growth rate of the next year.

The fossil fuel emissions increased from $6.8 \mathrm{PgC} \mathrm{yr}^{-1}$ in 2001 to $9.8 \mathrm{PgC} \mathrm{yr}^{-1}$ in 2015 . The fossil fuel emissions in 2014 and 2015 are almost equal, but the 2015 atmospheric growth rate of $2.98 \pm 0.09 \mathrm{ppm} \mathrm{yr}^{-1}$ is much higher, compared to $1.99 \pm 0.09 \mathrm{ppm} \mathrm{yr}^{-1}$ in 2014. As shown in Fig. 3, CTE2016 assigns this anomaly to a smaller net uptake by the biosphere, and in a lesser extent to a smaller net ocean uptake. Biomass burning emissions have also slightly increased between 2014 and 2015.

Over the period 2001-2015, especially 2011 and 2014 stand out with high net land uptake, and the net carbon sinks in 2002, 2003 and 2005 were relatively low (Fig. 3). Figure 4 shows the annual development of the cumulative anomalies of the net natural carbon fluxes (biosphere and ocean sinks, and the emissions from biomass burning). These anomalies are the deviations from the 2001-2015 mean. In 2011 and 2014 , the sinks were relatively larger throughout the year. The year 2015 had higher than average net uptake in summer, but this effect was canceled by a reduced net uptake in the remainder of the year.

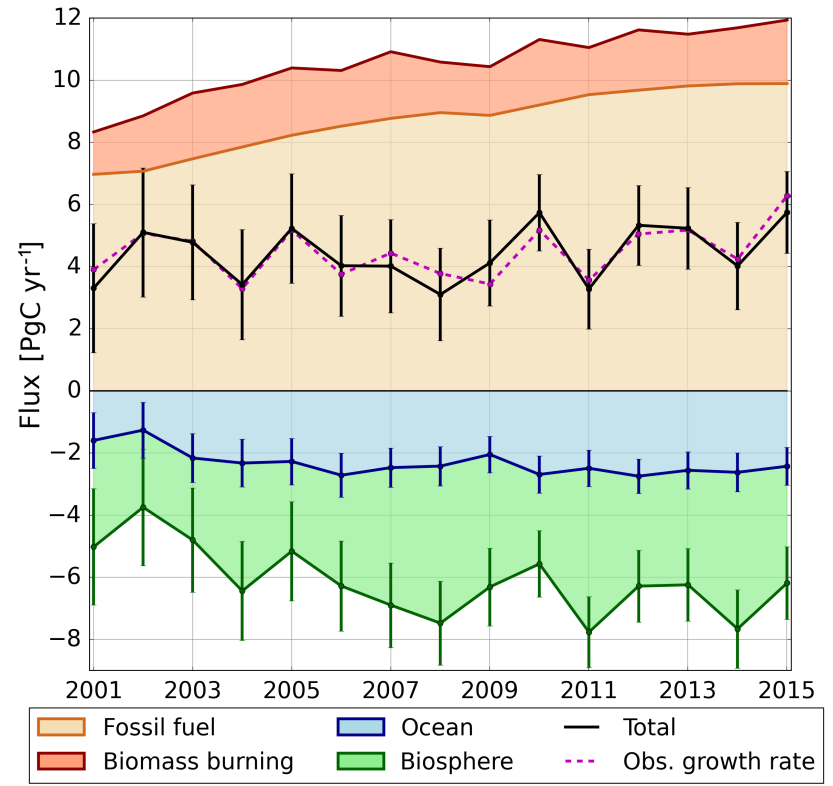

Figure 3. Global annual carbon balance estimated with CTE2016 for the period 2001-2015. Global ocean (blue) and biosphere (green) sinks are indicated as negative values and represent net uptake from the atmosphere. The error bars represent the annual $1 \sigma$ uncertainty, based on the average weekly covariances (more information on the error estimates in CarbonTracker in given in Sect. 3.4). Fossil fuel (orange) and biomass burning (red) emissions are not optimized. The total flux (black line) is the sum of the four components. The observed global annual atmospheric $\mathrm{CO}_{2}$ growth rate from the NOAA network (dashed magenta line) was converted from $\mathrm{ppm} \mathrm{yr}^{-1}$ using a conversion factor of $2.12 \mathrm{PgC} \mathrm{ppm}^{-1}$ (Prather et al., 2012).

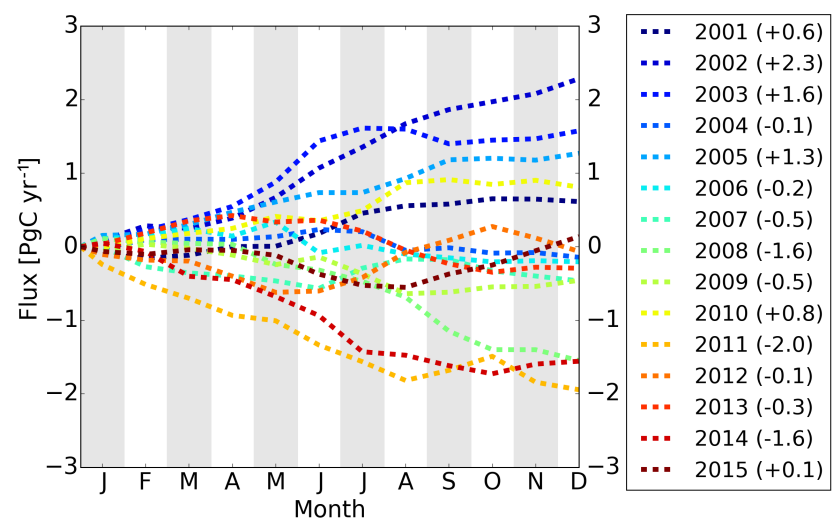

Figure 4. Monthly development of the cumulative annual anomalies in the global natural carbon fluxes (biosphere and ocean net sinks and biomass burning emissions). Anomalies are calculated from the mean over 2001-2015 for each year, thereby removing the average seasonal cycle. Negative numbers indicate years with larger than average net uptake and positive numbers represent years with smaller than average net uptake. 

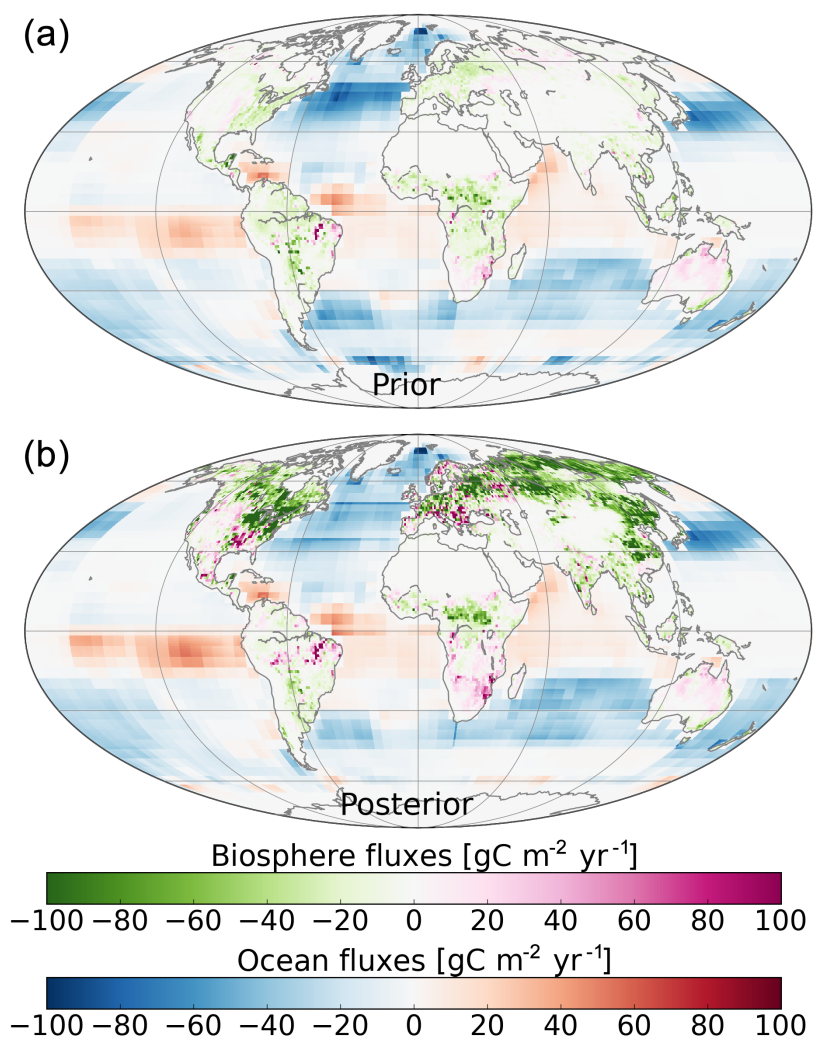

Figure 5. Global fluxes averaged over 2001-2015 for the prior estimate (a) and posterior/optimized estimates (b). Ocean and biosphere fluxes are shown on different color scales in $\mathrm{gC} \mathrm{m}^{-2} \mathrm{yr}^{-1}$. Biosphere fluxes include imposed biomass burning emissions.

Both natural sinks show an increasing trend over the period 2001-2015. The average net ocean sink slightly increased from $-1.9 \pm 0.8 \mathrm{PgC} \mathrm{yr}^{-1}$ in $2001-2003$ to $-2.5 \pm$ $0.1 \mathrm{PgC} \mathrm{yr}^{-1}$ in 2013-2015. The average net land sink (including biomass burning emissions) increased from $-1.8 \pm$ 1.0 to $-2.3 \pm 0.8 \mathrm{PgC} \mathrm{yr}^{-1}$ over the same time periods. Global maps of the ocean and biosphere fluxes (including biomass burning emissions) for the prior and posterior estimates averaged over the 2001-2015 period are shown in Fig. 5. The average posterior net biosphere sink (excluding biomass burning emissions) over 2001-2015 of $-3.8 \mathrm{PgC} \mathrm{yr}^{-1}$ is larger compared to the prior estimate of $-2.4 \mathrm{PgC} \mathrm{yr}^{-1}$. The sink especially increases in the Northern Hemisphere. The average net ocean sink of $-2.3 \mathrm{PgC} \mathrm{yr}^{-1}$ is lower than the prior estimate of $-2.7 \mathrm{PgC} \mathrm{yr}^{-1}$, and also the trend in the ocean sink decreases from a prior estimate of

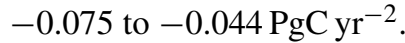

Figure 6 shows the latitudinal distribution of the average and $\mathrm{SD}$ of the residuals of the simulated minus observed $\mathrm{CO}_{2}$ mole fractions for all assimilated observations. With the exception of a few sites, the remaining biases are generally small and well below $1 \mathrm{ppm}$. The SD is largest in the Northern Hemisphere mid latitudes. The mean bias over all sites

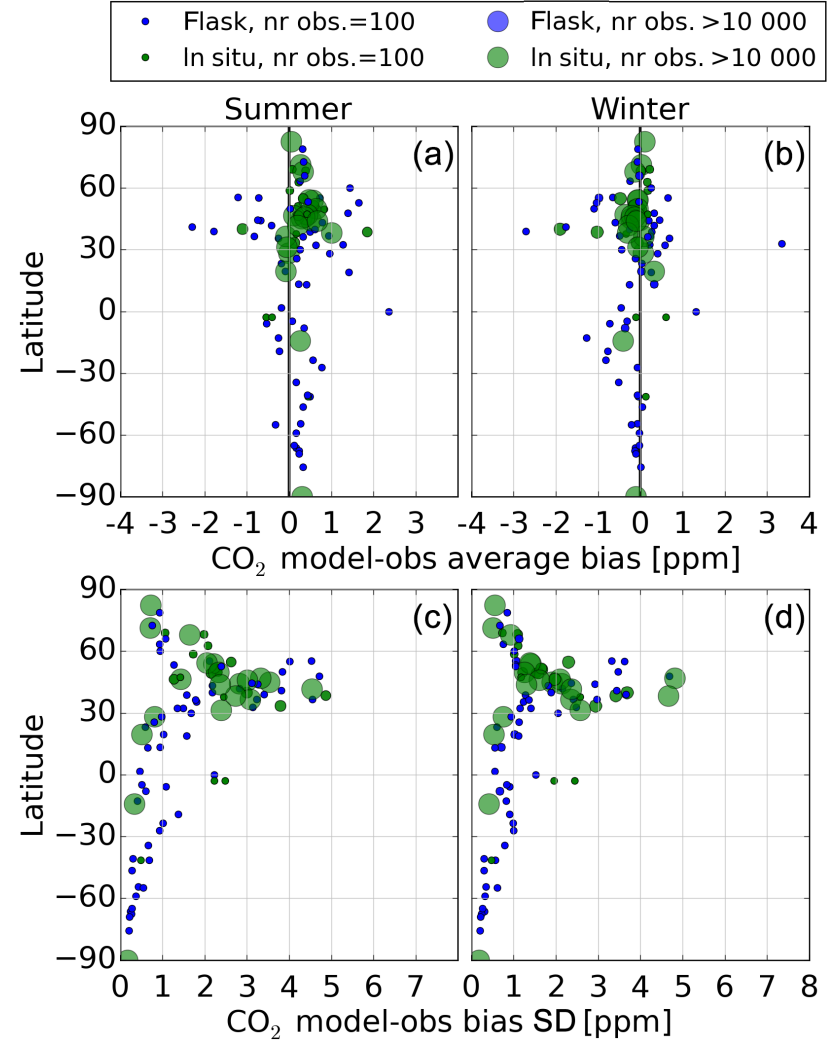

Figure 6. Latitudinal distribution of the average posterior residuals (a, b) and their SDs (c, d) per site over the period 2001-2015, for Northern Hemisphere summer $(\mathbf{a}, \mathbf{c})$ and winter $(\mathbf{b}, \mathbf{d})$. The residuals are calculated as the difference of the simulated minus observed $\mathrm{CO}_{2}$ mole fractions for all assimilated observations. Assimilated values do not include $\mathrm{CO}_{2}$ mole fractions of which their observed forecasted value exceeds 3 times the prescribed model-data mismatch.

is $0.027 \pm 0.67 \mathrm{ppm}$, and the average of the absolute values of the biases is $0.31 \pm 0.59 \mathrm{ppm}$. There is a difference in the bias between the summer and winter, as the wintertime observations are generally better represented in CarbonTracker because of the lower variability in the $\mathrm{CO}_{2}$ concentrations in winter, together with lower transport errors because of the difficulties in representing the smaller-scale convective transport during summer. CTE2016 overestimates the $\mathrm{CO}_{2}$ mole fractions in the Northern Hemisphere summer and the average bias is $0.31 \pm 0.89 \mathrm{ppm}$. In the Northern Hemisphere winter this is $-0.13 \pm 0.65 \mathrm{ppm}$.

Although CTE2016 optimizes fluxes on the global scale, carbon fluxes can also be estimated for smaller (eco)regions. Figure 7 shows the net carbon sink of the European forest ecoregion over the period 2001-2015, together with the emissions from fossil fuels from the same region. Forest areas and human activities strongly overlap in Europe (on $1^{\circ} \times 1^{\circ}$ resolution). In most of the years the forests take up carbon from the atmosphere and thereby partly compensate 
Table 2. Version information for CarbonTracker Europe simulations, with details on used setup including prior fluxes, observations, meteorological data and TM5 setup. References are provided in Sect. 3.1 and in the footnotes.

\begin{tabular}{|c|c|c|c|c|c|}
\hline Version ID & State vector & Biosphere/Fire ${ }^{a}$ & Fossil fuel & Observations $^{\mathrm{b}}$ & TM5/Meteo \\
\hline CTE2016 & Gridded & SiBCASA-GFED4 3 hourly & Carbones + GCP & ObsPack GVplus 2.1 & EI-convec \\
\hline CTE2016-FT ${ }^{\mathrm{d}}$ & Gridded & SiBCASA-GFED4 3 hourly & Carbones $+\mathrm{GCP}^{\mathrm{e}}$ & ObsPack GVplus $1.0+$ NRT & EI-convec \\
\hline CTE2015 & Gridded & SiBCASA-GFED4 3 hourly & Carbones $+\mathrm{GCP}^{\mathrm{f}}$ & ObsPack GVplus 1.0 & EI-convec \\
\hline CTE2014 & Gridded & SiBCASA-GFED4 monthly & Carbones & ObsPack Prototype $1.0 .4 \mathrm{~b}$ & EI-convec \\
\hline CTE2013 & Gridded & SiBCASA-GFED4 monthly & Carbones & ObsPack Prototype 1.0.3 & EI-newslopes ${ }^{g}$ \\
\hline CTE2013-OD ${ }^{\mathrm{h}}$ & Ecoregion & SiBCASA-GFED4 monthly & Miller $^{\mathrm{i}}+$ IER & ObsPack Prototype 1.0.3 & OD \\
\hline CTE2008 & Ecoregion & CASA-GFED $2^{\mathrm{j}}$ monthly & Miller & Pre-ObsPack and CarboEurope & $\mathrm{OD}\left(\mathrm{glb} 6^{\circ} \times 4^{\circ}\right)^{\mathrm{k}}$ \\
\hline
\end{tabular}

a Time resolution for the biosphere fluxes is either 3 hourly or monthly, while fire emissions are daily. ${ }^{\mathrm{b}}$ ObsPack products are available at

https://www.esrl.noaa.gov/gmd/ccgg/obspack/index.html. ${ }^{c}$ Global total fossil fuel emissions are scaled to the values included in the global carbon budget (Le Quéré et al., 2016) of the Global Carbon Project (GCP) for 2000-2015. ${ }^{\mathrm{d}}$ FT stands for Fast-Track, since inclusion in Le Quéré et al. (2016) required completion of the analysis before all observations became available. ${ }^{\mathrm{e}}$ Same as c, but using values from Le Quéré et al. (2015a) for 2010-2014, and Le Quéré et al. (2016) for 2015. ${ }^{\mathrm{f}}$ Same as e, for 2010-2014. ${ }^{\mathrm{g}}$ Newslopes refers to the updated slopes scheme in TM5, based on simulations with SF $_{6} \cdot{ }^{\mathrm{h}}$ Irregular version ID covers 2001-2010. ${ }^{\mathrm{i}}$ https://www.esrl.noaa.gov/gmd/ccgg/carbontracker/CT2016_doc.php\#tth_sEc4.1. $\mathrm{j}$ van der Werf et al. (2006) ${ }^{\mathrm{k}}$ The standard setup for TM5 is with a global spatial resolution of $3^{\circ} \times 2^{\circ}$ and two zoom regions over Europe and North America of $1^{\circ} \times 1^{\circ}$. Only for CTE2008 we used a global resolution of $6^{\circ} \times 4^{\circ}$ with a two-way nested zoom over Europe of $3^{\circ} \times 2^{\circ}$ and $1^{\circ} \times 1^{\circ}$.

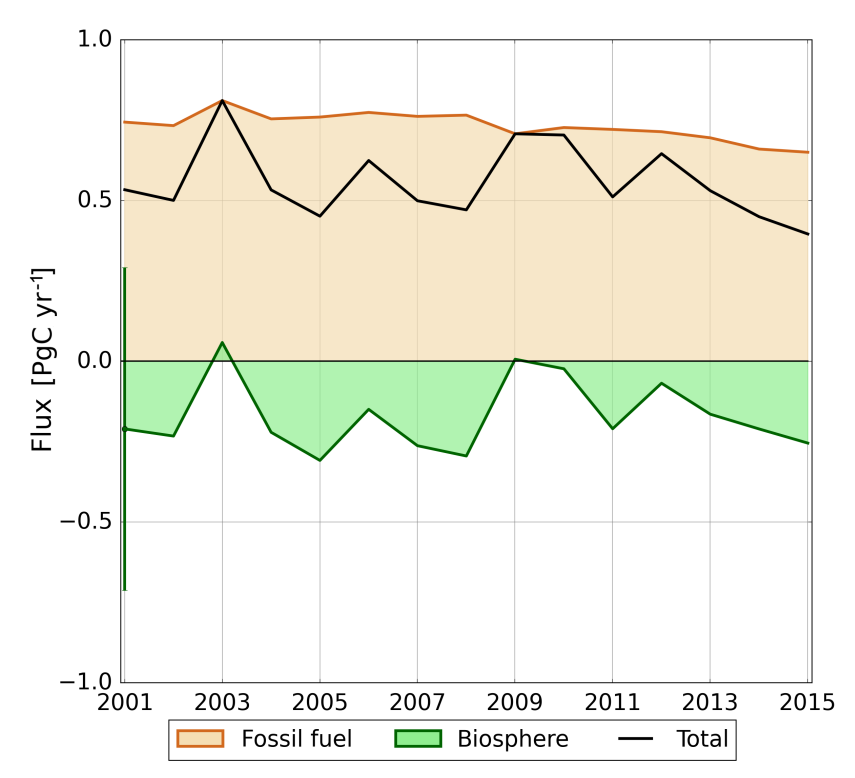

Figure 7. Annual carbon balance for European forests estimated with CTE2016 for the period 2001-2015. The net biosphere (green) sink is shown together with the fossil fuel (orange) emission from the same region. The error bar represents the annual $1 \sigma$ uncertainty, based on the average weekly covariances, and is shown only for 2001 for clarity (more information on the error estimates in CarbonTracker in given in Sect. 3.4). The total flux (black line) is the sum of the components.

the emissions. The average European carbon sink over 20012015 is $0.17 \pm 0.11 \mathrm{PgC} \mathrm{yr}^{-1}$, with some interannual variability and especially in years with droughts, like 2003 or 2010, the net European forest carbon sink is reduced to zero. Other (eco)regions in Europe (specifically grasslands) are close to neutral, while croplands can add up to a small source in some years. Our forest carbon sink is in good agreement with Janssens et al. (2003), but not with the space-based estimate from Reuter et al. (2014), who find a larger sink in European forests.

\subsection{Comparison of CTE2016 with previous releases}

The first release of carbon flux estimates from CTE was in 2008 (CTE2008). Table 2 gives an overview of the different versions of CTE. Generally, the version IDs include the year in which the version is released and the simulation covers the years from 2001 until the year before the release date (e.g. CTE2008 covers 2001-2007, while CTE2013-OD is an exception and covers 2001-2010). Simulations start in 2000, which is discarded and seen as a spin-up of the calculations. CTDAS (Sect. 2) was used for all versions from CTE2013OD. Since 2014, CTE results have been included in the annual updates of the global carbon budget published by the GCP (CTE2014, CTE2015, CTE2016-FT in resp. Le Quéré et al., 2015a, b, 2016).

From version CTE2008 to version CTE2016, several changes have been implemented. Most of the prior fluxes have been changed, except for the ocean prior fluxes, and the amount of observations and observational sites has increased. The most significant updates are (1) the implementation of the gridded state vector from version CTE2013 (Sect. 3.2), and (2) changes in the TM5 meteorology, including (a) changing from operational data from the ECMWF to using ERA-Interim reanalysis driver data (Dee et al., 2011), and (b) the use of the convective entrainment and detrainment fluxes directly from ECMWF from version CTE2014, instead of using the previous Tiedtke convection scheme.

The differences in the estimated natural carbon fluxes (ocean and biosphere including biomass burning emissions) between the different versions are shown in the left panel of Fig. 8 for selected regions for their overlapping period 20012007. The posterior uncertainty in CarbonTracker can be estimated by different approaches. The right panel includes the fluxes for a single region (northern land) together with two 

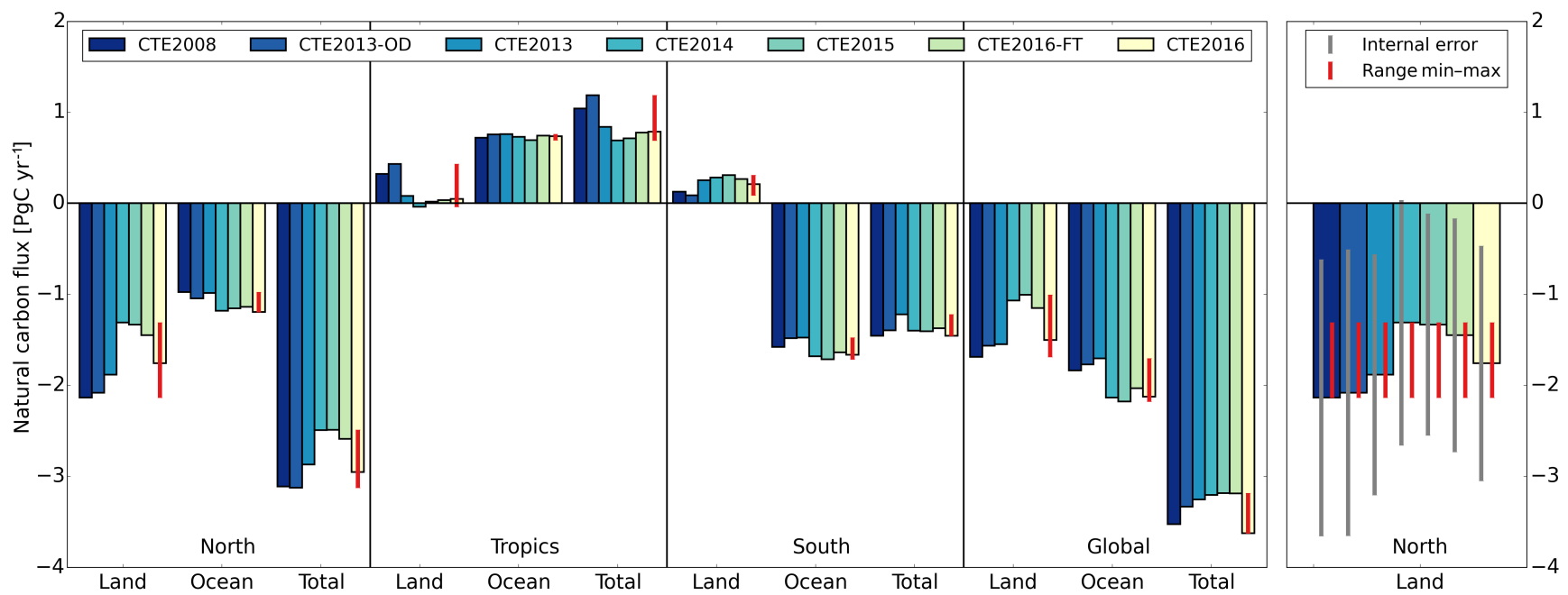

Figure 8. Average natural carbon flux estimates for different CTE versions for selected regions for the period 2001-2007 (left panel). The fluxes are the sum of the biosphere and ocean fluxes and biomass burning emissions. Two alternative uncertainty estimates are given for a selected region (right panel). The first is the internal error based on the average weekly posterior covariances $(n=418)$, while the second is representing the range between the different realizations of the inversion $(n=7)$. The second option is applied as the posterior uncertainty estimate per region in the left panel.

options for the uncertainty estimate. The first option shows the internal error based on the weekly posterior covariance matrix. A new prior covariance is included for each new week in the inversion, not taking into account information on the uncertainty (reduction) in the previous weeks. This results in a unrealistically large error estimate due to the absence of temporal correlation of the covariance in combination with the short assimilation window. The advantage is that fluxes from different regions remain uncoupled in new weeks. Alternatively, the uncertainty of an inversion can be estimated by the range between estimates from several different realizations (e.g. Peylin et al., 2013). The second option in Fig. 8 shows the range between the seven versions of CarbonTracker Europe. This is our preferred option and is also used in Peters et al. (2010) and van der Laan-Luijkx et al. (2015). The resulting carbon fluxes from these versions show differences based on the choices made in their setups. In the most recent version CTE2016, we have updated the fossil fuel emissions over the total period 2000-2015 to match the total global emissions used in GCP (Sect. 3.1). These higher emissions lead to larger net carbon sinks, especially in the Northern Hemisphere. Following from the uncertainty estimate taken as the range of the different versions, we can state that the change between CTE2008-CTE2013 to CTE2014CTE2016-FT has a significant effect on the resulting carbon flux estimates, which is a result of the used convective fluxes. The distribution of the sinks over the hemispheres shifted from the north to tropics and from the land to the oceans. With the updated convection, the land sink is especially decreased in the Northern Hemisphere, and the ocean sink is slightly increased in both the Northern and Southern hemispheres.

\section{Overview of applications using CTDAS}

Besides global $\mathrm{CO}_{2}$ fluxes as presented in Sect. 3, the CTDAS framework has also been used in several applications with focus on different regions or different greenhouse gases and related tracers. We developed a dedicated version of CTDAS focusing on the Amazon carbon balance: CT-SAM (van der Laan-Luijkx et al., 2015). With CT-SAM we found that the response of the Amazon carbon balance to the 2010 drought was twofold: the net biospheric uptake decreased and the emissions from biomass burning doubled. The total reduction of the net carbon uptake was $0.24-0.50 \mathrm{PgC} \mathrm{yr}^{-1}$ and turned the balance from carbon sink to source. We also developed a multi-tracer version of CTDAS including both $\mathrm{CO}_{2}$ and $\delta^{13} \mathrm{CO}_{2}$ (van der Velde, 2015; van der Velde et al., 2017). Using these combined signals together allowed optimization of both carbon fluxes and the isotope discrimination parameters. The results showed that isotope discrimination was decreased during severe droughts leading to an increase in intrinsic water use efficiency of up to $25 \%$.

CTDAS was also used to develop $\mathrm{CO}_{2}$ data assimilations systems with a specific focus on Asia and China in particular. This region is highly relevant in the carbon cycle due to the large $\mathrm{CO}_{2}$ emissions from fossil fuel combustion. Zhang et al. (2014a, b) showed that Chinese terrestrial ecosystems took up $0.33 \mathrm{PgC}^{-1}$ on average during $2001-2010$, thereby compensating approximately $20 \%$ of the total $\mathrm{CO}_{2}$ emissions from fossil fuel combustion from China. For Asia in to- 
tal, this effect is even larger: during 2006-2010 the Asian net terrestrial land $\mathrm{CO}_{2}$ sink was $-1.56 \mathrm{PgC} \mathrm{yr}^{-1}$, which is about $37 \%$ of the Asian fossil fuel emissions $\left(+4.15 \mathrm{PgC} \mathrm{yr}^{-1}\right)$. Jiang et al. (2016) suggest that the Chinese net terrestrial $\mathrm{CO}_{2}$ uptake is increasing over the past decades. This is also confirmed by Thompson et al. (2016), a study based on seven atmospheric inversions including CTE2014, which shows that the net annual $\mathrm{CO}_{2}$ sink in East Asia increased between 1996-2001 and 2008-2012 by $0.56(0.30-0.81) \mathrm{PgC} \mathrm{yr}^{-1}$, accounting for $35 \%$ of the increase in the global land biosphere sink.

CarbonTracker Europe results have been included in several studies focusing on different aspects of the carbon cycle. CTE2014 has e.g. been included in a study of the 2012 drought in the USA (Wolf et al., 2016), where a warm spring led to increased net biospheric carbon uptake, compensating for the reduction in net carbon uptake in the following summer drought. In this analysis, it was also shown that the use of CTE2014 with the new gridded state vector and the 3-hourly resolution of the prior biosphere fluxes was better suited to detect anomalies in the timing of the start of the growing season, compared to CT2013B (NOAA).

Babenhauserheide et al. (2015) evaluate the differences between two data assimilation approaches for $\mathrm{CO}_{2}$ : the ensemble Kalman smoother approach of CTDAS and the TM54DVar method. Several aspects of the data assimilation are addressed including the choices made in the window length for CarbonTracker and sensitivity to observational coverage. The carbon flux estimates from both optimization methods show increasing agreement with observational density. The CarbonTracker approach was shown to result in a higher bias between the simulated and observed mole fractions in remote regions (e.g. South Pole), given its 5 week assimilation window. On the other hand, the TM5-4DVar method with its longer window is more susceptible to changes in observational coverage and has larger correlations between regions. Increasing CarbonTracker's window length to improve the bias at remote sites could also result in incorrect projection of fluxes in regions with limited observational coverage, specifically the tropics (e.g. van der Laan-Luijkx et al., 2015).

CTDAS is used at the Finnish Meteorological Institute (FMI) for the development of CarbonTracker Europe Methane $\left(\mathrm{CTE}-\mathrm{CH}_{4}\right)$ and is used to perform global methane inversions (Tsuruta et al., 2015, 2017). Both anthropogenic and biosphere emissions of $\mathrm{CH}_{4}$ are simultaneously constrained by global atmospheric $\mathrm{CH}_{4}$ mole fraction observations. The mean global total emissions during 2000-2012 were estimated to be $516 \pm 51 \mathrm{Tg} \mathrm{CH}_{4}$ per year of which about $60 \%$ are of anthropogenic origin and $30 \%$ are biogenic. Emissions in the 2007-2012 period were on average $18 \mathrm{Tg} \mathrm{CH}_{4}$ per year larger compared to the 2001-2006 period.

CTDAS has also been used for the optimization of transport properties of the underlying TM5 model using observations of $\mathrm{SF}_{6}$ (van der Veen, 2013). Previous studies demonstrated that many models, including TM5, poorly simulate the $\mathrm{SF}_{6}$ gradients between the Northern Hemisphere $(\mathrm{NH})$ and Southern Hemisphere (SH), which is mainly controlled by transport across the intertropical convergence zone (ITCZ). After lifting by the strong convective motions near the tropics, $\mathrm{SF}_{6}$-rich air from the $\mathrm{NH}$ can make its way into the SH through lateral outflow. Many models underestimate the efficiency of this process, as it is often not resolved numerically on the grid scales used for global modeling. As a result, the interhemispheric exchange time of these models is too slow, and gradients in $\mathrm{SF}_{6}$ between the $\mathrm{NH}$ and $\mathrm{SH}$ are overestimated. Inversions with $\mathrm{SF}_{6}$ improved the northsouth transport of TM5 by accelerating its horizontal subgrid scale transport in the convection scheme. The results were used as an intermediate solution for the setup of TM5 in CTE2013 (indicated as newslopes in Table 2) before switching from the old Tiedtke convection scheme to using the convective fluxes directly from ECMWF.

All CTDAS applications mentioned above used TM5 as the observation operator and were applied to the global scale. Other applications on regional scales are currently being developed using different transport models. CTDASLagrange (developed at University of Groningen) combines CTDAS with a high-resolution Lagrangian transport model, the Stochastic Time-Inverted Lagrangian Transport model driven by the Weather Forecast and Research meteorological fields (WRF-STILT) (He et al., 2017). This system assimilates atmospheric observations of $\mathrm{CO}_{2}$ and in the future also $\mathrm{COS}$ to constrain gross primary production and ecosystem respiration for North America. Footprints for each $\mathrm{CO}_{2}$ and $\mathrm{COS}$ observation are precalculated, making this a computationally more efficient method than using an Eulerian model. Resulting $\mathrm{CO}_{2}$ flux estimates for North America in 2010 are comparable to estimates from CTE2016 and CT2016 (He et al., 2017). A second regional application focuses on Switzerland, and is developed at ETH Zürich. CTDAS is combined with the new tracer transport module of the regional numerical weather prediction model COSMO, and is used to estimate carbon fluxes in Switzerland, making use of $\mathrm{CO}_{2}$ observations from four new measurement sites around Switzerland (Liu, 2017; Oney et al., 2015). The resulting $\mathrm{CO}_{2}$ flux estimates match well with the bottom-up estimates.

\section{Conclusions and outlook}

We demonstrated the use of our new data assimilation framework: the CarbonTracker Data Assimilation Shell (CTDAS). This framework allows flexible setup of different components of the data assimilation system and can be used in a wide range of applications. We have shown the most recent developments for the CarbonTracker Europe $\mathrm{CO}_{2}$ system: CTE2016, especially the implementation of the gridded state vector. We have shown results from CTE2016 on 
the global scale. Resulting flux estimates and $\mathrm{CO}_{2}$ mole fractions are available from http://www.carbontracker.eu. We will provide annual updates and in the near future these will also be made available through the ICOS Carbon Portal (http://www.icos-cp.eu).

Upcoming developments for CTDAS include, e.g., the expansion with more options for regional and urban applications with the use of different transport models as observations operator. We are also evaluating the implementation of the new version of TM5: TM5-mp (massive parallel). TM5$\mathrm{mp}$ can be run parallel over grid cells instead of tracers and thereby offers the possibility to efficiently simulate the transport on global $1^{\circ} \times 1^{\circ}$ resolution. Other developments in TM5 include the implementation of online meteorology. We will furthermore focus on new options for optimization methods and covariance structure. We are studying methods to account for temporal correlation in the state covariance matrix. Also we will study the effects of using different data assimilation window lengths (e.g. Kang et al., 2012; Liu et al., 2012) on our resulting fluxes. Finally, we will also focus on the European carbon balance by specifically re-evaluating the fluxes from croplands (Combe, 2016).

Code and data availability. The CTDAS code (current revision r1479) is included as Supplement and is open access under GNU General Public License version 3. The actual CTDAS code is continuously updated and under version control (SVN) on a local server at Wageningen University and Research. Access can be granted after contacting the main developers. The documentation of the code (user manual) prepared with SPHINX (see Sect. 2.5) is available at http://www.carbontracker.eu/ctdas. The input data used for CTDAS depends per application, and can be made available upon request.

\section{The Supplement related to this article is available online at https://doi.org/10.5194/gmd-10-2785-2017- supplement.}

Author contributions. ITvdLL and WP prepared the manuscript with contributions from all co-authors. WP developed CTDAS, with contributions from the other authors. CTE2008, CTE2013-OD, CTE2013, CTE2014, CTE2015 and CTE2016-FT, CTE2016 simulations were performed by ITvdLL and WP.

Competing interests. The authors declare that they have no conflict of interest.

Acknowledgements. The authors thank the contributing laboratories for providing the atmospheric $\mathrm{CO}_{2}$ observations from a global network of measurement sites through ObsPack products GLOBALVIEWplus version 1.0, 2.0 and 2.1, NRT v3.0, and previous prototypes. We acknowledge the NOAA CarbonTracker team, specifically Andy Jacobson, for the fruitful collaboration.
CTE2016 simulations (and previous releases) have been performed using a grant for computing time (SH-312-14) from the Netherlands Organization for Scientific Research (NWO). Ingrid T. van der Laan-Luijkx was funded by OCW/NWO for ICOS-NL, and is currently funded by a NWO Veni grant (016.Veni.171.095). Wouter Peters is supported by an ERC consolidator grant (649087). Part of the results included were supported by the GEOCARBON project (EU FP7/2007-2013, grant agreement 283080). Huilin Chen's contribution is supported by the NOAA contract NA13OAR4310082.

Edited by: Carlos Sierra

Reviewed by: two anonymous referees

\section{References}

Anderson, J., Hoar, T., Raeder, K., Liu, H., Collins, N., Torn, R., and Avellano, A.: The data assimilation research testbed a community facility, B. Am. Meteorol. Soc., 90, 1283-1296, https://doi.org/10.1175/2009BAMS2618.1, 2009.

Arellano, A. F., Hess, P. G., Edwards, D. P., and Baumgardner, D.: Constraints on black carbon aerosol distribution from Measurement of Pollution in the Troposphere (MOPITT) CO, Geophys. Res. Lett., 37, L17801, https://doi.org/10.1029/2010GL044416, 2010.

Babenhauserheide, A., Basu, S., Houweling, S., Peters, W., and Butz, A.: Comparing the CarbonTracker and TM5-4DVar data assimilation systems for $\mathrm{CO}_{2}$ surface flux inversions, Atmos. Chem. Phys., 15, 9747-9763, https://doi.org/10.5194/acp-159747-2015, 2015.

Basu, S., Guerlet, S., Butz, A., Houweling, S., Hasekamp, O., Aben, I., Krummel, P., Steele, P., Langenfelds, R., Torn, M., Biraud, S., Stephens, B., Andrews, A., and Worthy, D.: Global $\mathrm{CO}_{2}$ fluxes estimated from GOSAT retrievals of total column $\mathrm{CO}_{2}$, Atmos. Chem. Phys., 13, 8695-8717, https://doi.org/10.5194/acp13-8695-2013, 2013.

Bruhwiler, L. M. P., Michalak, A. M., Peters, W., Baker, D. F., and Tans, P.: An improved Kalman Smoother for atmospheric inversions, Atmos. Chem. Phys., 5, 2691-2702, https://doi.org/10.5194/acp-5-2691-2005, 2005.

Chevallier, F., Ciais, P., Conway, T. J., Aalto, T., Anderson, B. E., Bousquet, P., Brunke, E. G., Ciattaglia, L., Esaki, Y., Fröhlich, M., Gomez, A., Gomez-Pelaez, A. J., Haszpra, L., Krummel, P. B., Langenfelds, R. L., Leuenberger, M., Machida, T., Maignan, F., Matsueda, H., Morguí, J. A., Mukai, H., Nakazawa, T., Peylin, P., Ramonet, M., Rivier, L., Sawa, Y., Schmidt, M., Steele, L. P., Vay, S. A., Vermeulen, A. T., Wofsy, S., and Worthy, D.: $\mathrm{CO}_{2}$ surface fluxes at grid point scale estimated from a global 21 year re-analysis of atmospheric measurements, J. Geophys. Res., 115, D21307, https://doi.org/10.1029/2010JD013887, 2010.

Combe, M.: Modeling the coupled exchange of water and $\mathrm{CO}_{2}$ over croplands, $\mathrm{PhD}$ thesis, Wageningen University, Wageningen, the Netherlands, 2016.

Dee, D. P., Uppala, S. M., Simmons, A. J., Berrisford, P., Poli, P., Kobayashi, S., Andrae, U., Balmaseda, M. A., Balsamo, G., and Bauer, P.: The ERA-Interim reanalysis: configuration and perfor- 
mance of the data assimilation system, Q. J. Roy. Meteor. Soc., 137, 553-597, https://doi.org/10.1002/qj.828, 2011.

Dlugokencky and Tans: Trends in Atmospheric Carbon Dioxide, NOAA/ESRL, available at: www.esrl.noaa.gov/gmd/ccgg/ trends/, last access: 12 May 2017.

EDGAR4.2 Database: Emission Database for Global Atmospheric Research (EDGAR), release version 4.2, European Commission, Joint Research Centre (JRC)/PBL Netherlands Environmental Assessment Agency, available at: http://edgar.jrc.ec.europa.eu (last access: 14 July 2017), 2011.

Giglio, L., Randerson, J. T., and van der Werf, G. R.: Analysis of daily, monthly, and annual burned area using the fourthgeneration global fire emissions database (GFED4), J. Geophys. Res.-Biogeo., 118, 317-328, https://doi.org/10.1002/jgrg.20042, 2013.

Gurney, K. R., Law, R. M., Denning, A. S., Rayner, P. J., Baker, D., Bousquet, P., Bruhwiler, L., Chen, Y. H., Clals, P., Fan, S., Fung, I. Y., Gloor, M., Heimann, M., Higuchi, K., John, J., Maki, T., Maksyutov, S., Masarie, K., Peylin, P., Prather, M., Pak, B. C., Randerson, J., Sarmiento, J., Taguchi, S., Takahashi, T., and Yuen, C. W.: Towards robust regional estimates of $\mathrm{CO}_{2}$ sources and sinks using atmospheric transport models, Nature, 415, 626-630, https://doi.org/10.1038/415626a, 2002.

He, W., van der Velde, I. R., Andrews, A. E., Sweeney, C., Tans, P., van der Laan-Luijkx, I. T., Baker, I., Ju, W., Peters, W., and Chen, H.: CTDAS-Lagrange v1.0: A high-resolution data assimilation system for regional carbon dioxide observations, in preparation, 2017.

Huijnen, V., Williams, J., van Weele, M., van Noije, T., Krol, M., Dentener, F., Segers, A., Houweling, S., Peters, W., de Laat, J., Boersma, F., Bergamaschi, P., van Velthoven, P., Le Sager, P., Eskes, H., Alkemade, F., Scheele, R., Nédélec, P., and Pätz, H.-W.: The global chemistry transport model TM5: description and evaluation of the tropospheric chemistry version 3.0, Geosci. Model Dev., 3, 445-473, https://doi.org/10.5194/gmd-3445-2010, 2010.

Jacobson, A. R., Mikaloff Fletcher, S. E., Gruber, N., Sarmiento, J. L., and Gloor, M.: A joint atmosphere-ocean inversion for surface fluxes of carbon dioxide: 1. Methods and global-scale fluxes, Global Biogeochem. Cy., 21, GB1019, https://doi.org/10.1029/2005GB002556, 2007.

Janssens, I. A., Freibauer, A., Ciais, P., Smith, P., Nabuurs, G. J., Folberth, G., Schlamadinger, B., Hutjes, R. W. A., Ceulemans, R., Schulze, E. D., Valentini, R., and Dolman, A. J.: Europe's terrestrial biosphere absorbs 7 to $12 \%$ of European anthropogenic $\mathrm{CO}_{2}$ emissions, Science, 300, 1538-1542, https://doi.org/10.1126/science.1083592, 2003.

Jiang, F., Chen, J. M., Zhou, L., Ju, W., Zhang, H., Machida, T., Ciais, P., Peters, W., Wang, H., Chen, B., Liu, L., Zhang, C., Matsueda, H., and Sawa, Y.: A comprehensive estimate of recent carbon sinks in China using both top-down and bottom-up approaches, Sci. Rep., 6, 22130, https://doi.org/10.1038/srep22130, 2016.

Joos, F., Roth, R., Fuglestvedt, J. S., Peters, G. P., Enting, I. G., von Bloh, W., Brovkin, V., Burke, E. J., Eby, M., Edwards, N. R., Friedrich, T., Frölicher, T. L., Halloran, P. R., Holden, P. B., Jones, C., Kleinen, T., Mackenzie, F. T., Matsumoto, K., Meinshausen, M., Plattner, G.-K., Reisinger, A., Segschneider, J., Shaffer, G., Steinacher, M., Strassmann, K., Tanaka, K., Tim- mermann, A., and Weaver, A. J.: Carbon dioxide and climate impulse response functions for the computation of greenhouse gas metrics: a multi-model analysis, Atmos. Chem. Phys., 13, 2793 2825, https://doi.org/10.5194/acp-13-2793-2013, 2013.

Kang, J.-S., Kalnay, E., Miyoshi, T., Liu, J., and Fung, I.: Estimation of surface carbon fluxes with an advanced data assimilation methodology, J. Geophys. Res., 117, D24101, https://doi.org/10.1029/2012JD018259, 2012.

Krol, M., Houweling, S., Bregman, B., van den Broek, M., Segers, A., van Velthoven, P., Peters, W., Dentener, F., and Bergamaschi, P.: The two-way nested global chemistry-transport zoom model TM5: algorithm and applications, Atmos. Chem. Phys., 5, 417432, https://doi.org/10.5194/acp-5-417-2005, 2005.

Le Quéré, C., Moriarty, R., Andrew, R. M., Canadell, J. G., Sitch, S., Korsbakken, J. I., Friedlingstein, P., Peters, G. P., Andres, R. J., Boden, T. A., Houghton, R. A., House, J. I., Keeling, R. F., Tans, P., Arneth, A., Bakker, D. C. E., Barbero, L., Bopp, L., Chang, J., Chevallier, F., Chini, L. P., Ciais, P., Fader, M., Feely, R. A., Gkritzalis, T., Harris, I., Hauck, J., Ilyina, T., Jain, A. K., Kato, E., Kitidis, V., Klein Goldewijk, K., Koven, C., Landschützer, P., Lauvset, S. K., Lefèvre, N., Lenton, A., Lima, I. D., Metzl, N., Millero, F., Munro, D. R., Murata, A., Nabel, J. E. M. S., Nakaoka, S., Nojiri, Y., O’Brien, K., Olsen, A., Ono, T., Pérez, F. F., Pfeil, B., Pierrot, D., Poulter, B., Rehder, G., Rödenbeck, C., Saito, S., Schuster, U., Schwinger, J., Séférian, R., Steinhoff, T., Stocker, B. D., Sutton, A. J., Takahashi, T., Tilbrook, B., van der Laan-Luijkx, I. T., van der Werf, G. R., van Heuven, S., Vandemark, D., Viovy, N., Wiltshire, A., Zaehle, S., and Zeng, N.: Global Carbon Budget 2015, Earth Syst. Sci. Data, 7, 349-396, https://doi.org/10.5194/essd-7-349-2015, 2015a.

Le Quéré, C., Moriarty, R., Andrew, R. M., Peters, G. P., Ciais, P., Friedlingstein, P., Jones, S. D., Sitch, S., Tans, P., Arneth, A., Boden, T. A., Bopp, L., Bozec, Y., Canadell, J. G., Chini, L. P., Chevallier, F., Cosca, C. E., Harris, I., Hoppema, M., Houghton, R. A., House, J. I., Jain, A. K., Johannessen, T., Kato, E., Keeling, R. F., Kitidis, V., Klein Goldewijk, K., Koven, C., Landa, C. S., Landschützer, P., Lenton, A., Lima, I. D., Marland, G., Mathis, J. T., Metzl, N., Nojiri, Y., Olsen, A., Ono, T., Peng, S., Peters, W., Pfeil, B., Poulter, B., Raupach, M. R., Regnier, P., Rödenbeck, C., Saito, S., Salisbury, J. E., Schuster, U., Schwinger, J., Séférian, R., Segschneider, J., Steinhoff, T., Stocker, B. D., Sutton, A. J., Takahashi, T., Tilbrook, B., van der Werf, G. R., Viovy, N., Wang, Y.-P., Wanninkhof, R., Wiltshire, A., and Zeng, N.: Global carbon budget 2014, Earth Syst. Sci. Data, 7, 47-85, https://doi.org/10.5194/essd-7-47-2015, 2015b.

Le Quéré, C., Andrew, R. M., Canadell, J. G., Sitch, S., Korsbakken, J. I., Peters, G. P., Manning, A. C., Boden, T. A., Tans, P. P., Houghton, R. A., Keeling, R. F., Alin, S., Andrews, O. D., Anthoni, P., Barbero, L., Bopp, L., Chevallier, F., Chini, L. P., Ciais, P., Currie, K., Delire, C., Doney, S. C., Friedlingstein, P., Gkritzalis, T., Harris, I., Hauck, J., Haverd, V., Hoppema, M., Klein Goldewijk, K., Jain, A. K., Kato, E., Körtzinger, A., Landschützer, P., Lefèvre, N., Lenton, A., Lienert, S., Lombardozzi, D., Melton, J. R., Metzl, N., Millero, F., Monteiro, P. M. S., Munro, D. R., Nabel, J. E. M. S., Nakaoka, S.-I., O'Brien, K., Olsen, A., Omar, A. M., Ono, T., Pierrot, D., Poulter, B., Rödenbeck, C., Salisbury, J., Schuster, U., Schwinger, J., Séférian, R., Skjelvan, I., Stocker, B. D., Sutton, A. J., Takahashi, T., Tian, H., Tilbrook, B., van der Laan-Luijkx, I. T., van der Werf, G. 
R., Viovy, N., Walker, A. P., Wiltshire, A. J., and Zaehle, S.: Global Carbon Budget 2016, Earth Syst. Sci. Data, 8, 605-649, https://doi.org/10.5194/essd-8-605-2016, 2016.

Liu, J., Fung, I., Kalnay, E., Kang, J.-S., Olsen, E. T., and Chen, L.: Simultaneous assimilation of AIRS $\mathrm{Xco}_{2}$ and meteorological observations in a carbon climate model with an ensemble Kalman filter, J. Geophys. Res., 117, D05309, https://doi.org/10.1029/2011JD016642, 2012.

Liu, Y.: CarbonTracker Switzerland: A high resolution Ensemble Kalman Filter System to constrain biospheric $\mathrm{CO}_{2}$ fluxes in central Europe, DISS. ETH NO. 23728, PhD thesis, ETH Zürich, Zürich, Switzerland, https://doi.org/10.3929/ethz-a-010893766, 2017.

ObsPack: Cooperative Global Atmospheric Data Integration Project, Multi-laboratory compilation of atmospheric carbon dioxide data for the period 1957-2015, obspack_co2_1_GLOBALVIEWplus_v2.1_2016-09-02, NOAA Earth System Research Laboratory, Global Monitoring Division, https://doi.org/10.15138/G3059Z, 2016.

Olson, J. S., Watts, J. A., and Allison, L. J.: Major World Ecosystem Complexes Ranked by Carbon in Live Vegetation: A Database (NDP-017), Tech. rep., Carbon Dioxide Information Analysis Center, Oak Ridge National Laboratory, Oak Ridge, Tennessee, https://doi.org/10.3334/CDIAC/lue.ndp017.2006, 2002.

Oney, B., Henne, S., Gruber, N., Leuenberger, M., Bamberger, I., Eugster, W., and Brunner, D.: The CarboCount $\mathrm{CH}$ sites: characterization of a dense greenhouse gas observation network, Atmos. Chem. Phys., 15, 11147-11164, https://doi.org/10.5194/acp-15-11147-2015, 2015.

Peters, W., Miller, J. B., Whitaker, J., Denning, A. S., Hirsch, A., Krol, M. C., Zupanski, D., Bruhwiler, L., and Tans, P. P.: An ensemble data assimilation system to estimate $\mathrm{CO}_{2}$ surface fluxes from atmospheric trace gas observations, J. Geophys. Res., 110, 1-18, https://doi.org/10.1029/2005JD006157, 2005.

Peters, W., Jacobson, A. R., Sweeney, C., Andrews, A. E., Conway, T. J., Masarie, K., Miller, J. B., Bruhwiler, L. M. P., Pétron, G., Hirsch, A. I., Worthy, D. E. J., van der Werf, G. R., Randerson, J. T., Wennberg, P. O., Krol, M. C., and Tans, P. P.: An atmospheric perspective on North American carbon dioxide exchange: CarbonTracker, P. Natl. Acad. Sci. USA, 104, 1892518930, https://doi.org/10.1073/pnas.0708986104, 2007.

Peters, W., Krol, M. C., van der Werf, G. R., Houweling, S., Jones, C. D., Hughes, J., Schaefer, K., Masarie, K. A., Jacobson, A. R., Miller, J. B., Cho, C. H., Ramonet, M., Schmidt, M., Ciattaglia, L., Apadula, F., Heltai, D., Meinhardt, F., di Sarra, A. G., Piacentino, S., Sferlazzo, D., Aalto, T., Hatakka, J., Ström, J., Haszpra, L., Meijer, H. A. J., van der Laan, S., Neubert, R. E. M., Jordan, A., Rodó, X., Morguí, J.A., Vermeulen, A. T., Popa, E., Rozanski, K., Zimnoch, M., Manning, A. C., Leuenberger, M., Uglietti, C., Dolman, A. J., Ciais, P., Heimann, M., and Tans, P. P.: Seven years of recent European net terrestrial carbon dioxide exchange constrained by atmospheric observations, Glob. Change Biol., 16, 1317-1337, https://doi.org/10.1111/j.1365-2486.2009.02078.x, 2010.

Peylin, P., Law, R. M., Gurney, K. R., Chevallier, F., Jacobson, A. R., Maki, T., Niwa, Y., Patra, P. K., Peters, W., Rayner, P. J., Rödenbeck, C., van der Laan-Luijkx, I. T., and Zhang, X.: Global atmospheric carbon budget: results from an ensemble of atmospheric $\mathrm{CO}_{2}$ inversions, Biogeosciences, 10, 6699-6720, https://doi.org/10.5194/bg-10-6699-2013, 2013.

Prather, M. J., Holmes, C. D., and Hsu, J.: Reactive greenhouse gas scenarios: systematic exploration of uncertainties and the role of atmospheric chemistry, Geophys. Res. Lett., 39, L09803, https://doi.org/10.1029/2012GL051440, 2012.

Prinn, R. G., Weiss, R. F., Miller, B. R., Huang, J., Alyea, F. N., Cunnold, D. M., Fraser, P. J., Hartley, D. E., and Simmonds, P. G.: Atmospheric trends and lifetime of $\mathrm{CH}_{3} \mathrm{CCI}_{3}$ and global $\mathrm{OH}$ concentrations, Science, 269, 187-192, https://doi.org/10.1126/science.269.5221.187, 1995.

Raeder, K., Anderson, J. L., Collins, N., Hoar, T. J., Kay, J. E., Lauritzen, P. H., and Pincus, R.: DART/CAM: an ensemble data assimilation system for CESM atmospheric models, J. Climate, 25, 6304-6317, https://doi.org/10.1175/JCLI-D-11-00395.1, 2012.

Reuter, M., Buchwitz, M., Hilker, M., Heymann, J., Schneising, O., Pillai, D., Bovensmann, H., Burrows, J. P., Bösch, H., Parker, R., Butz, A., Hasekamp, O., O’Dell, C. W., Yoshida, Y., Gerbig, C., Nehrkorn, T., Deutscher, N. M., Warneke, T., Notholt, J., Hase, F., Kivi, R., Sussmann, R., Machida, T., Matsueda, H., and Sawa, Y.: Satellite-inferred European carbon sink larger than expected, Atmos. Chem. Phys., 14, 13739-13753, https://doi.org/10.5194/acp-14-13739-2014, 2014.

Rödenbeck, C., Houweling, S., Gloor, M., and Heimann, M.: $\mathrm{CO}_{2}$ flux history 1982-2001 inferred from atmospheric data using a global inversion of atmospheric transport, Atmos. Chem. Phys., 3, 1919-1964, https://doi.org/10.5194/acp-3-1919-2003, 2003.

Thompson, R. L., Patra, P. K., Chevallier, F., Maksyutov, S., Law, R. M., Ziehn, T., van der Laan-Luijkx, I. T., Peters, W., Ganshin, A., Zhuravlev, R., Maki, T., Nakamura, T., Shirai, T., Ishizawa, M., Saeki, T., Machida, T., Poulter, B., Canadell, J. G., and Ciais, P.: Top-down assessment of the Asian carbon budget since the mid 1990s, Nat. Commun., 7, 10724, https://doi.org/10.1038/ncomms10724, 2016.

Tiedtke, M.: A comprehensive mass flux scheme for cumulus parameterization in large-scale models, Mon. Weather Rev., 117, 1779-1800, https://doi.org/10.1175/15200493(1989)117<1779:ACMFSF>2.0.CO;2, 1989.

Tremolet, Y., Hofstadler, A., and Deconinck, W.: OOPS as a common framework for research and Operations, ECMWF 14th Workshop on Meteorological Operational Systems, Reading, UK, 18-20 November, available at: https://www.ecmwf.int/en/elibrary/ 13852-oops-common-framework-research-and-operations (last access: 14 July 2017), 2013.

Tsuruta, A., Aalto, T., Backman, L., Peters, W., Krol, M., van der Laan-Luijkx, I. T., Hatakka, J., Heikkinen, P., Duglokencky, E. J., Spahni, R., and Paramonova, N. N.: Evaluating atmospheric methane inversion model results for Pallas, northern Finland, Boreal Environ. Res., 20, 506-525, 2015.

Tsuruta, A., Aalto, T., Backman, L., Hakkarainen, J., van der LaanLuijkx, I. T., Krol, M. C., Spahni, R., Houweling, S., Laine, M., Dlugokencky, E., Gomez-Pelaez, A. J., van der Schoot, M., Langenfelds, R., Ellul, R., Arduini, J., Apadula, F., Gerbig, C., Feist, D. G., Kivi, R., Yoshida, Y., and Peters, W. Global methane emission estimates for 2000-2012 from CarbonTracker Europe- $\mathrm{CH}_{4}$ v1.0, Geosci. Model Dev., 10, 1261-1289, https://doi.org/10.5194/gmd-10-1261-2017, 2017. 
van der Laan-Luijkx, I. T., van der Velde, I. R., Krol, M. C., Gatti, L. V., Domingues, L. G., Correia, C. S. C., Miller, J. B., Gloor, M., van Leeuwen, T. T., Kaiser, J. W., Wiedinmyer, C., Basu, S., Clerbaux, C., and Peters, W.: Response of the Amazon carbon balance to the 2010 drought derived with CarbonTracker South America, Global Biogeochem. Cy., 29, 10921108, https://doi.org/10.1002/2014GB005082, 2015.

van der Veen, E.: Optimizing transport properties in TM5 using $\mathrm{SF}_{6}$, Master's thesis, Wageningen University, University of Twente, Enschede, the Netherlands, available at: http://essay. utwente.nl/65459/ (last access: 14 July 2017), 2013.

van der Velde, I. R.: Studying biosphere-atmosphere exchange of $\mathrm{CO}_{2}$ through Carbon-13 stable isotopes, $\mathrm{PhD}$ thesis, Wageningen University, Wageningen, the Netherlands, 2015.

van der Velde, I. R., Miller, J. B., Schaefer, K., van der Werf, G. R., Krol, M. C., and Peters, W.: Terrestrial cycling of ${ }^{13} \mathrm{CO}_{2}$ by photosynthesis, respiration, and biomass burning in SiBCASA, Biogeosciences, 11, 6553-6571, https://doi.org/10.5194/bg-116553-2014, 2014.

van der Velde, I. R., Miller, J. B., van der Molen, M. K., Tans, P. P., Vaughn, B. H., White, J. W. C., Schaefer, K., and Peters, W.: A multi-species data assimilation system to retrieve information on land-atmosphere exchange processes, Geosci. Model Dev. Discuss., https://doi.org/10.5194/gmd-2017-84, in review, 2017.

van der Werf, G. R., Randerson, J. T., Giglio, L., Collatz, G. J., Kasibhatla, P. S., and Arellano Jr., A. F.: Interannual variability in global biomass burning emissions from 1997 to 2004, Atmos. Chem. Phys., 6, 3423-3441, https://doi.org/10.5194/acp-6-34232006, 2006.

van der Werf, G. R., Randerson, J. T., Giglio, L., Collatz, G. J., Mu, M., Kasibhatla, P. S., Morton, D. C., DeFries, R. S., Jin, Y., and van Leeuwen, T. T.: Global fire emissions and the contribution of deforestation, savanna, forest, agricultural, and peat fires (1997-2009), Atmos. Chem. Phys., 10, 11707-11735, https://doi.org/10.5194/acp-10-11707-2010, 2010.
Wolf, S., Keenan, T. F., Fisher, J. B., Baldocchi, D. D., Desai, A. R., Richardson, A. D., Scott, R. L., Law, B. E., Litvak, M. E., Brunsell, N. A., Peters, W., and van der Laan-Luijkx, I. T.: Warm spring reduced carbon cycle impact of the 2012 US summer drought, P. Natl. Acad. Sci. USA, 113, 5880-5885, https://doi.org/10.1073/pnas.1519620113, 2016.

Zhang, H. F., Chen, B. Z., van der Laan-Luijkx, I. T., Chen, J., Xu, G., Yan, J. W., Zhou, L. X., Fukuyama, Y., Tans, P. P., and Peters, W.: Net terrestrial $\mathrm{CO}_{2}$ exchange over China during 2001-2010 estimated with an ensemble data assimilation system for atmospheric $\mathrm{CO}_{2}$, J. Geophys. Res., 119, 3500-3515, https://doi.org/10.1002/2013JD021297, 2014a.

Zhang, H. F., Chen, B. Z., van der Laan-Luijk, I. T., Machida, T., Matsueda, H., Sawa, Y., Fukuyama, Y., Langenfelds, R., van der Schoot, M., Xu, G., Yan, J. W., Cheng, M. L., Zhou, L. X., Tans, P. P., and Peters, W.: Estimating Asian terrestrial carbon fluxes from CONTRAIL aircraft and surface $\mathrm{CO}_{2}$ observations for the period 2006-2010, Atmos. Chem. Phys., 14, 5807-5824, https://doi.org/10.5194/acp-14-5807-2014, 2014b.

Zupanski, D., Denning, A. S., Uliasz, M., Zupanski, M., Schuh, A. E., Rayner, P. J., Peters, W., and Corbin, K. D.: Carbon flux bias estimation employing Maximum Likelihood Ensemble Filter (MLEF), J. Geophys. Res., 112, D17107, https://doi.org/10.1029/2006JD008371, 2007. 